\title{
Measuring Technical Efficiency of Construction Listed Companies Based on Different Distribution using Stochastic Frontier Model
}

\author{
${\text { Roslah } \operatorname{Arsad}^{1,2 *} \text { and Zaidi Isa }}^{2}$ \\ ${ }^{I}$ Faculty of Computer \& Mathematical Sciences, Universiti Teknologi MARA, Perak Branch, Tapah Campus, \\ Tapah Road, 35400 Perak, Malaysia \\ ${ }^{2}$ School of Mathematical Sciences, Faculty Sciences and Technology, Universiti Kebangsaan Malaysia, 43600 \\ UKM Bangi, Selangor, Malaysia
}

\begin{abstract}
This study investigated the technical efficiency and robustness of efficiency score rankings across two distributional assumptions for Cobb-Douglas production frontier model for 20 Malaysian construction companies over the period of 2013 to 2017. Stochastic frontier of Cobb-Douglas production function and maximum likelihood estimation technique applied to estimate the parameters with half-normal and truncated-normal distributions by a model with both time-variant and time-invariant inefficiency effects. Based on the likelihood ratio test, deviations from the efficient frontiers of function mainly recognized technical inefficiency, with a half-normal distribution for time-invariant inefficiency effect. This study shows that time did not contribute to efficiency performance over the short-investigated period. The Spearman rank correlation results of this study show that both distribution ranking for time-invariant inefficiency effect have a strong and significant relationship, while their rankings are quite consistent to distributional choice. The results also show that both efficiency scores are also diverse.
\end{abstract}

Keywords: Cobb-Douglas, Robustness, Efficiency, Financial Ratio, Stochastic Frontier

\section{INTRODUCTION}

Stock selection has been a challenging and interesting issue for decision makers such as investors. However, it is difficult to decide which stocks should be selected, because there are a large number of stocks available in the stock exchange market. Hence, decision makers must analyze and evaluate stock performance before making their final decision. One of the traditional approaches to evaluate the performance of the stocks is based on computational of financial ratio. Generally, a financial ratio is derived from company's financial statements such as balance sheet and income statement. These statements are able to provide information on financial status, identify internal strengths and weaknesses, and predict future financial performance and stability of a company.

Measurement of performance can also be defined in terms of a productivity ratio, which represents a production frontier used to define the relationship between the input and the output, whereas the capability of the inputs to be converted into outputs production process in achieving their economic objectives, such as maximization of production profit. If decision making units (DMUs) that represent productive entity operate on its production frontier, they are technically efficient and the value of technical efficiency is equal one. However they are not technically efficient if DMUs below the frontier and the technical efficiency score are less than one (Coelli et al., 2005).

In this study, Stochastic Frontier Analysis (SFA) method was used to measure the technical efficiency of DMUs. The reason for applying SFA approach in this study because it has the advantage allows for statistical tests to make hypotheses on production and degree inefficiency. The SFA model also allows better separation of noise and 
inefficiency error. Therefore, separation of inefficiency error from statistical noise requires specific assumptions about technical inefficiency; for example, assumptions about technical inefficiency are a half-normal distribution and normal distribution for statistical noise.

The types of distribution selections are guided by theoretical considerations and computational convenience. For instance, estimation of the frontier model is constructed in some software packages but not others. Estimated elasticity and technological change effects are robust to this change in the distributional assumption. In addition, different distributional assumption may give rise to different predictions of technical efficiency. However, when we rank the firms on the basis of predicted technical efficiencies, the rankings are often quite robust to distributional choice. In such cases, the principle of parsimony favors the simpler half-normal and exponential models (Coelli et al., 2005) .

A number of distributions have been assumed in the literature. The most commonly used are half-normal, exponential and truncated-normal distributions. Researchers tend to use half-normal and truncated-normal as inefficiency error distributions due to ease of estimation, interpretation, and the fact that technical estimates are similar for each distribution (Kirkley et al., 1995).

Although there is no consensus on the type of distribution one should choose to measure the inefficiency measure, most of works that are available in the literature suggest that different distributional assumptions tend to yield similar efficiency score (Mokhtar et al., 2006). According to Greene (1990), different distributions do not have much on impact efficiency score. Yane \& Berg (2013) and Altunbas \& Molyneux (1994), comparing four different distribution assumption (half-normal, truncated-normal, exponential and gamma distribution) for Japanese water utilities and German banks, respectively, discovered that efficiency ranking for their studies are quite consistent.

Hasan et al. (2012) employed the SFA model for the Bangladesh stock market for the period 2000-2008. Truncated-normal and half-normal were used as distributional choices and both variant and time-invariant inefficiency effects were estimated. Their studies revealed that the technical efficiency decreased gradually over the reference period. Yang (2010) used SFA to compute efficiency of 12 international airport from 1998-2006 and identified that inefficiency effects increased over the investigated period. Gong \& Sickles (1992) assumed that technical inefficiency is time-invariant in their studies. One justification is that firm specific inefficiency can be considered as an inherent and structural residual between observed data and the corresponding production frontier. Without violent changes in economic environments (i.e. deregulation), firm-specific efficiency and its relative rankings are not likely to change drastically over short time periods.

The goal of this study is to compute the technical efficiency and examine the robustness of efficiency score ranking across two distributional assumptions (halfnormal and truncated-normal) using the Cobb-Douglas production function on the data of 20 construction companies listed in Bursa Malaysia. The second section of this paper discusses the methodology of this research.

Discussion on theoretical concept effect of SFA models, selection of variables, and construction of empirical SFA model for this study are also mentioned in this section. The third section covers the results and discussions of this study. Finally, conclusions and suggestions for future studies are presented in the last section.

\section{MATERIALS AND METHODS}

This paper uses SFA methods in computing technical efficiency of samples data from companies' construction traded in Bursa Malaysia based on short panel data from the period 2013 till 2017. Calculations of maximum likelihood were computed using the R-programming employing frontier package (Coelli et al., 2017).

The 20 selected construction listed companies are Ahmad Zaki Resources Berhad (AZRB),Benalec Holdings Berhad (BENL), Bina Puri Holding Berhad (BPUR), Brem Holding Berhad (BREM), Crest Builder Holding Berhad CREH), DKLS Industries Bhd (DKLS), Ekovest Berhad (EKOV), Ho Hup Construction Company Bhd (HHCS), Gadang Holdings Berhad (GADA), Malaysia Resources Corporation Bhd (MRCB), Muhibbah Engineering (M) Bhd (MUHI), PLB Engineering Bhd (PLBE), Prinsiptek 
Corporation Berhad (PSIP), SBC Corporation Berhad (SIAH), Sycal Ventures Berhad (SYCA), TRC Synergy Berhad (TRCG),TRlpcBerhad (TRLPC),TSR Capital Berhad (TSRP), WCT Holding Berhad (WCTE) and YTL Corporation Berhad (YTLS).

\section{A. SFA Model with Efficiency Effect}

A SFA model, as proposed by Aigner et al. (1977) and Meeusen \&Van Den Broeck (1977), can be expressed as follows:

$$
\ln \left(\mathrm{y}_{\mathrm{i}}\right)=x \beta+v_{i}-u_{i}, \quad i=1,2, \ldots . ., N
$$

In this function, $y_{i}$ is the observed output of DMU $i, x_{i}$ is a $(1 \times K)$ vector of the consumed input of DMU $i, \beta$ is a $(1 \times K)$ vector of unknown parameters to be estimated.

Battese \& Coelli (1992) proposed a SFA production function model for panel data which time varying efficiencies permitted. The model assumed a traditional random error, $v_{\text {it }}$ and a non-negative error term representing the technical inefficiency, $u_{\text {it }}$. Here, $v_{\text {it }}$ is assumed to be independent and identically distributed (i.i.d) as $v_{i t} \sim \mathrm{N}\left(\mathrm{o}, \sigma_{v}^{2}\right)$ and captures statistical noise, measurement error, and other random events that are beyond the company's control. The non-negative error term $u_{\text {it }}$ captures the technical inefficiency in production to be independent and identically distributed (i.i.d).

The parameterized of the log-likelihood function using:

$$
\sigma^{2}=\sigma_{v}^{2}+\sigma_{u}^{2} ; \gamma=\sqrt{\frac{\sigma_{u}^{2}}{\sigma^{2}}}
$$

Parameters gamma ( $\gamma$ ) shown in equation (2), must be in the range between 0 and 1 . If the value of $\gamma=0$, it means that all the deviation from the frontier are due to random error (noise). However, when $\gamma=\mathbf{1}$, this means that all deviations are resulted from technical inefficiency. Given the specification of the SFA model in equation (1), the production's technical efficiency of the $i^{\text {th }}$ firm at a time $\boldsymbol{t}$, is the ratio of the actual to potential as follows:

$$
T E_{i}=\exp \left(-u_{i t}\right)
$$

Battese \& Coelli (1992) proposed to represent the preceding as follows:

$$
U_{i t}=\exp (-\eta(t-T)) u_{i}
$$

Where $\eta$ is a parameter to be estimated, and $u_{i}$ is assumed to be i.i.d as truncations at zero of the $N\left(\mu, \sigma_{u}^{2}\right)$ distribution. When parameter eta, $\eta$ to be zero, it provides a time-invariant inefficiency effect model.

All the selected input variables in production factors were derived from literature studies and the output selections were based on the DuPont analysis concept. DuPont analysis is one of the methods for companies to analyze its profitability performance using Return on Equity (ROE). ROE is the production output, where the DuPont formula is:

$$
\mathrm{ROE}=\frac{\text { NetProfit Margin } \times \text { Total AT }}{\text { Equity ratio }}
$$

ROE is the amount of net income returned as a percentage of shareholder equity; it is used to measure corporate profitability by disclosing the generated profit of a company to the shareholder's fund. ROEs using DuPont calculation are different from common calculation ROEs, because DuPont reveals the relationship between profitability (net profit margin), assets management (total assets turnover) and financial leverage (debt ratio) in determining the ROE.

For inputs selection, this study has chosen:

Asset Turnover, AT $\left(x_{1}\right)$ : AT specifies the company's degree of success in utilizing its assets to produce revenues.

Market Capitalization, $\mathrm{MC}\left(x_{2}\right)$ : MC is the overall value of a company's issues stock capital as stipulated by its stock price in the stock market. MC is considered based on the ordinary stocks number in issue and it is multiplied by the prior day's closing stock price.

Debt to equity ratio, $\operatorname{DE}\left(x_{3}\right): \mathrm{DE}$ ratio measures a company's financial leverage and shows company's debt that is used to finance its assets in relation to the value of shareholders equity. 


\section{B. Empirical SFA model}

The empirical SFA model can be expressed with the specification of Cobb-Douglas functional form as follows:

$\ln \left(\mathrm{y}_{\mathrm{it}}\right)=\beta_{\mathrm{o}}+\beta_{1} \ln x_{1 \mathrm{it}}+\beta_{2} \ln x_{2 \mathrm{it}}+\beta_{3} \ln x_{3 \mathrm{it}}$

$+\left(v_{i t}-u_{i t}\right)$

Where subscripts $i$ and $t$ represent the $i^{\text {th }}$ company for $i=1,2, \ldots \ldots, 20$, and $t^{\text {th }}$ year of observation for $t=1,2, \ldots \ldots ., 5$, where parameter

$y_{i t}=$ individual of return on equity,

$\beta=$ vector of unknown parameters to estimate, $x_{1 i t}=$ asset turnover,

$x_{2 i t}=$ market capitalization,

$x_{3 i t}=$ debt to equity ratio,

$u_{i t}=$ technical inefficiency in production, (assumes to be independent and identically distributed (i.i.d) and also assumes as half-normal or truncated normal distribution),

$v_{i t}=$ the statistical noise, measurement error and other random events that are beyond the company's control (assumes as normal distribution).

A hypothesis test was performing using the likelihood ratio to construct the SFA model appropriate with the dataset of this study. The following hypotheses were tested in this paper:

i. To test whether technical inefficiencies effects exist over the time in the model;

ii. To test whether technical inefficiency effects has halfnormal or truncated-normal distribution; iii. To test whether the inefficiency effects are timeinvariant.

The hypotheses tests are based on the generalized likelihood-ratio (LR) test. The test statistics $\mathrm{LR}=-2\left[\ln _{\mathrm{R}}\left(\mathrm{H}_{\mathrm{O}}\right)-\ln \mathrm{L}_{\mathrm{U}}\left(\mathrm{H}_{1}\right)\right] \quad$ conforms to $\chi^{2}(J)$, where $\ln \mathrm{L}_{\mathrm{R}}\left(\right.$ or $\left.\mathrm{H}_{\mathrm{O}}\right)$ and $\ln \mathrm{L}_{\mathrm{U}}\left(\right.$ or $\left.\mathrm{H}_{1}\right)$ denote the values of the restricted and unrestricted for log-likelihood functions respectively, and $J$ is the number of restrictions.

The null hypothesis $H_{0}$ is rejected at the $\alpha \%$ level of significance if the likelihood-ratio statistic exceeds the critical value $\chi_{1-\alpha}^{2}(J)$.

\section{RESULTS AND DISCUSSIONS}

The maximum-likelihood method was used to estimate the parameters using Cobb-Douglas production function. The ordinary least square value likelihood function is -131.76 . For constructing the SFA model, a likelihood test was conducted using hypothesis testing.

The first hypothesis is to recognize the possibility of technical inefficiency effects over

the time period. The hypothesis is $H_{0}: \gamma=0$ versus $H_{1}: \gamma>0$. Based on Table 1, the log-likelihood of the restricted model is -131.76 , and value for unrestricted model is -111.65. The log-likelihood ratio test statistics value is $-2[-131.76-(-111.65)]=40.22$. This value exceeded the critical $5 \%$ value of 7.82 . Therefore, the null hypothesis was rejected, implying that there is a technical inefficiency effect in the model.

Table 1.Maximum-Likelihood Estimations of Stochastic Production Model with Time-Variant

\begin{tabular}{|c|c|c|c|c|c|c|c|c|c|}
\hline & & \multicolumn{4}{|c|}{ Truncated-Normal } & \multicolumn{4}{c|}{ Half-Normal } \\
\hline Variables & & Coefficients & S.E & $\begin{array}{c}Z \\
\text { value }\end{array}$ & $\operatorname{Pr}(>|\mathrm{z}|)$ & Coefficients & S.E & $\begin{array}{c}\mathrm{Z} \\
\text { value }\end{array}$ & $\operatorname{Pr}(>|\mathrm{z}|)$ \\
\hline Constant & $\beta_{0}$ & -1.869 & 0.994 & -1.879 & 0.0601838 & 0.099 & 2.721 & 0.036 & 0.970981 \\
\hline Assets turnover & $\beta_{1}$ & 0.489 & 0.173 & 2.832 & $0.0046193^{* *}$ & 0.544 & 0.191 & 2.852 & $0.004338^{* *}$ \\
\hline $\begin{array}{c}\text { Market } \\
\text { capitalization }\end{array}$ & $\beta_{2}$ & 0.235 & 0.054 & 4.338 & $1.441 \mathrm{e}-05^{* * *}$ & 0.113 & 0.141 & 0.801 & 0.423243 \\
\hline $\begin{array}{c}\text { Debt to equity } \\
\text { ratio }\end{array}$ & $\beta_{3}$ & 0.644 & 0.121 & 5.334 & $9.573 \mathrm{e}-08^{* * *}$ & 0.712 & 0.128 & 5.559 & $\begin{array}{c}2.718 \mathrm{e}^{*} \\
08^{* * *}\end{array}$ \\
\hline Sigma-squared & $\sigma^{2}$ & 1.068 & 0.353 & 3.020 & $0.003 \mathrm{e}-05^{* * *}$ & 2.560 & 0.923 & 2.774 & $0.005539^{* * *}$ \\
\hline Gamma & $\gamma$ & 0.681 & 0.080 & 8.466 & $<2.2 \mathrm{e}-16^{* * *}$ & 0.853 & 0.060 & 14.152 & $<2.2 \mathrm{e}-16^{* * * *}$ \\
\hline
\end{tabular}




\begin{tabular}{|c|c|c|c|c|c|c|c|c|c|}
\hline $\mathrm{Mu}$ & $\mu$ & 1.705 & 0.459 & 3.716 & $0.0002021^{* * *}$ & 0 & 0 & 0 & 0 \\
\hline Eta & $\eta$ & -0.053 & 0.027 & $\begin{array}{c}- \\
1.998\end{array}$ & 0.0457170 & -0.057 & 0.040 & -1.430 & 0.152696 \\
\hline Log-likelihood & & \multicolumn{8}{|c|}{-111.65} \\
\hline
\end{tabular}

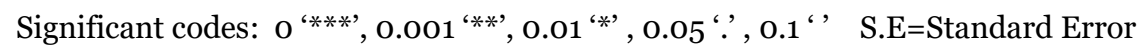

Table 2. Maximum Likelihood Estimations of Stochastic Production Model with Time-Invariant

\begin{tabular}{|c|c|c|c|c|c|c|c|c|c|}
\hline & & \multicolumn{4}{|c|}{ Truncated-Normal } & \multicolumn{4}{|c|}{ Half-Normal } \\
\hline Variables & & Coefficients & S.E & $\begin{array}{c}\mathrm{Z} \\
\text { value }\end{array}$ & $\operatorname{Pr}(>|z|)$ & Coefficients & S.E & $\begin{array}{c}\mathrm{Z} \\
\text { value }\end{array}$ & $\operatorname{Pr}(>|z|)$ \\
\hline Constant & $\beta_{0}$ & -1.485 & 1.062 & -1.399 & 0.0161799 & 0.458 & 2.714 & 0.169 & 0.8658326 \\
\hline Assets turnover & $\beta_{1}$ & 0.635 & 0.161 & 3.943 & $\begin{array}{c}8.064 \mathrm{e}- \\
05^{* * * *}\end{array}$ & 0.679 & 0.179 & 3.789 & $\underset{* * *}{0.0001514^{*}}$ \\
\hline $\begin{array}{c}\text { Market } \\
\text { capitalization }\end{array}$ & $\beta_{2}$ & 0.229 & 0.053 & $4 \cdot 316$ & $\begin{array}{l}1.590 \mathrm{Oe}- \\
05^{* * * *}\end{array}$ & 0.104 & 0.140 & 0.740 & 0.4591453 \\
\hline $\begin{array}{l}\text { Debt to equity } \\
\text { ratio }\end{array}$ & $\beta_{3}$ & 0.639 & 0.136 & 4.700 & $\begin{array}{c}2.599 \mathrm{e}- \\
06^{* * * *} \\
\end{array}$ & 0.736 & 0.130 & 5.643 & $1.67 \mathrm{e}-08^{* * *}$ \\
\hline Sigma-squared & $\sigma^{2}$ & 1.032 & 0.486 & 2.121 & 0.0339058 & 2.256 & 0.832 & 2.713 & $0.006668^{* *}$ \\
\hline Gamma & $\gamma$ & 0.657 & 0.112 & 5.838 & $\begin{array}{c}5.273 \mathrm{e}- \\
09^{* * * *}\end{array}$ & 0.831 & 0.071 & 11.701 & $<2.2 \mathrm{e}-16^{* * *}$ \\
\hline $\mathrm{Mu}$ & $\mu$ & 1.646 & 0.498 & $3 \cdot 305$ & $0.000949^{* * *}$ & o & o & o & o \\
\hline Eta & $\eta$ & o & o & o & o & o & o & o & o \\
\hline Log-likelihood & & \multicolumn{4}{|c|}{-113.22} & \multicolumn{4}{|c|}{-114.80} \\
\hline
\end{tabular}

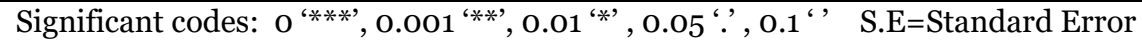

Table 1 also shows value of parameter $\gamma$ for truncatednormal distribution is 0.681 . The values are consistent with the earlier hypothesis test, as the deviations are more due to the technical inefficiency effect.

Second was to identify types of distribution for technical inefficiency term $\mathcal{u}$, which has a half-normal distribution (restricted model) and truncated-normal distribution (unrestricted model). The hypothesis is $H_{0}: \mu=0$; versus $H_{1}: \mu \neq 0$. The log-likelihood value, as shown in Table 2, for the restricted model is -114.80 , and the log-likelihood function of the unrestricted model is-113.22. Thus, the $\begin{array}{llll}\text { likelihood ratio statistic is } & \text { s }\end{array}$ $-2[-11480-(-11322)]=3.16$, which is less than $\alpha=5 \%$; for a critical value of 3.84 . Due to the fact that the null hypotheses is failed to reject, we concluded that the halfnormal distribution is preferable to be associated with technical inefficiency effects. The final test is to determine whether inefficiency effects are time-invariant. The test are done by running two models; one model without the parameter $\eta(\eta=0)$ which assumed to have non-time varying over the time period and another model with the parameter $\eta$.

Referring on Table 1 and Table 2, the log-likelihood function of the restricted model is -114.80 , and value of unrestricted model is -113.68. The log-likelihood ratio statistic is $-2[-\mathbf{1 1 4 8 0}-(-\mathbf{1 1 3 6 8})]=\mathbf{2 . 2 4}$; which is less than $\alpha=5 \%$; critical value of 3.84. Therefore, the null hypothesis failed to reject, which implies excluding $\eta$ in the model (time-invariant). This result is appropriate because this study use short panel data.

After testing theses three hypothesis, we followed model time-invariant effects with half-normal distribution as shown in Table 2. The table provides parameter estimates and value $\gamma$ shows 0.831 where the deviation from the frontier mainly recognized to technical inefficiency. This value is supported by an earlier hypothesis test that the deviations are due to technical inefficiency. Based on this parameter, technical efficiency will be computed and compared with truncated-normal distribution. 
Table 3 provides ranking of companies by different distribution with time-invariant effect. Some companies such as TRLPC, HHCS, SIAH, DKLS, WCTE and BPUR have similar rankings and for others, their efficiency rankings are quite consistent when applying both distribution assumptions. The top ranked company is TRLPC and the bottom ranked is BPUR. The efficiency score for both distribution assumptions are also different from the mean efficiency with half-normal higher than truncated-normal distribution, as shown in Table 3 and Figure 1.

Further investigation computed the Spearman rank correlation coefficients to determine relationship ranking for both methods. The results reveal that the correlation coefficient rank between both methods is 0.979 , with p-value less than significance level $\alpha=0.05$.

Table 3. Ranking of Companies by Distribution

\begin{tabular}{|c|c|c|c|c|}
\hline & \multicolumn{2}{|c|}{ Half-Normal } & \multicolumn{2}{c|}{ Truncated-Normal } \\
\hline Rank & Eff. Score & DMU & Eff. Score & DMU \\
\hline 1 & 0.868 & TRLPC & 0.731 & TRLPC \\
\hline 2 & 0.867 & HHCS & 0.645 & HHCS \\
\hline 3 & 0.697 & SIAH & 0.369 & SIAH \\
\hline 4 & 0.643 & EKOV & 0.31 & GADA \\
\hline 5 & 0.615 & GADA & 0.308 & EKOV \\
\hline 6 & 0.507 & BREM & 0.282 & CREH \\
\hline 7 & 0.478 & DKLS & 0.258 & DKLS \\
\hline 8 & 0.476 & CREH & 0.234 & BREM \\
\hline 9 & 0.403 & MRCB & 0.201 & MUHI \\
\hline 10 & 0.398 & MUHI & 0.176 & MRCB \\
\hline 11 & 0.391 & WCTE & 0.173 & WCTE \\
\hline 12 & 0.321 & YTLS & 0.171 & PLBE \\
\hline 13 & 0.273 & PLBE & 0.147 & SYCA \\
\hline 14 & 0.267 & SYCA & 0.146 & TSRP \\
\hline 15 & 0.237 & TSRP & 0.123 & YTLS \\
\hline 16 & 0.205 & BENL & 0.117 & AZRB \\
\hline 17 & 0.188 & AZRB & 0.095 & BENL \\
\hline 18 & 0.158 & TRCG & 0.095 & PSIP \\
\hline 19 & 0.133 & PSIP & 0.093 & TRCG \\
\hline 20 & 0.04 & BPUR & 0.033 & BPUR \\
\hline
\end{tabular}
distributions. Time-invariant effects with a half-normal for inefficiency error distribution is the preferable model for computing the technical efficiency for this study.

The ranking of this study is robust to distributional choice, even though both values of efficiency scores are diverse. There exists a strong relationship between rankings of both distributional choices. The time-invariant inefficiency is thought to be more appropriate when dealing with a short time period, and the efficiency is thought unlikely to vary much over

Finally, for further research, long panel data should be used to study inefficiency effects across time and to check the consistency of efficiency ranking for the time varying effect. 


\section{REFERENCES}

Aigner, D., Lovell, C. A. K. and Schmidt, P. "Formulation and estimation of stochastic frontier production function models,” J. Econom., vol. 6, no. 1, pp. 21-37, 1977.

Altunbas, Y. and Molyneux, P. "Sensitivity of stochastic frontier estimation to distributional assumptions: the case of the German banks," Inst. Eur. Financ. Pap., 1994.

Battese, G. E. and Coelli, T. J. "Frontier production functions, technical efficiency and panel data: with application to paddy farmers in India,” J. Product. Anal., vol. 3, no. 1-2, pp. 153-169, 1992.

Coelli, A. T., Henningsen, A. and Henningsen, M. A. "Package " frontier,", 2017.

Coelli, T. J., Rao, D. S. P., O’Donnell, C. J. and Battes, G. E. An introduction to efficiency and productivity analysis, vol. 41, no. 3. 2005 .

Gong, B. and Sickles, R. C. "Finite sample evidence on the performance of stochastic frontiers and data envelopment analysis using panel data *," vol. 51, no. April 1987, pp. 259-284, 1992.

Greene, W. H. "A Gamma-Distributed Stochastic Frontier Model William H.," vol. 46, pp. 141-163, 1990.

Hasan, Z., Kamil, A. A., Mustafa, A. and Baten, A. "Stochastic Frontier Model Approach for Measuring Stock Market Efficiency with Different Distributions," vol. 7, no. 5, 2012.

Kirkley, J. E., Squires, D. and Strand, I. E. "Assessing Technical Efficiency in Commercial Fisheries : The MidAtlantic Sea Scallop Fishery,” vol. 77, no. August, 1995.

Meeusen, W. and van Den Broeck, J. "Efficiency Estimation from Cobb-Douglas Production Functions with Composed Error," Int. Econ. Rev. (Philadelphia)., vol. 18, no. 2, pp. 435-444, 1977.

Mokhtar, H. S. A., Abdullah, N. and Al-Habshi, S. M. "Efficiency of Islamic banking in Malaysia: A stochastic frontier approach,” J. Econ. Coop., vol. 27, no. 2, pp. 3770, 2006.

Yane, S. and Berg, S. "Sensitivity analysis of efficiency rankings to distributional assumptions: applications to Japanese water utilities,” Appl. Econ., vol. 45, no. 17, pp. 2337-2348, 2013.
Yang, H. H. "Measuring the efficiencies of Asia-Pacific international airports - Parametric and non-parametric evidence," Comput. Ind. Eng., vol. 59, no. 4, pp. 697702, 2010. 